\title{
An Aerological Study of Heavy Rainfall Over West and Central Japan during Early Summer 1953
}

\author{
By K. Mohri \\ Japan Meteorological Agency, Tokyo \\ (Manuscript received 9 July, 1956)
}

\begin{abstract}
High and middle tropospheric conditions of temperature and wind fields are analysed in detail for heavy rainfall cases of 26 June and 17 July 1953 . In these cases the subtropical upper frontal zone is observed in the vertical cross sections in its well defined form. It is suggested that the vertical motion associated with this upper frontal zone might be one of the factors which induce the heavy rainfall over west and central Japan during the rainy season in early summer.
\end{abstract}

\section{Introduction}

Early summer is a climatological rainy season over Japan and vicinity. This rainy season (called Bai-u) usually commences at the beginning of June and ends at the middle of July. During the rainy season the surface synoptic situation over Japan and vicinity is characterized by a semi-stationary surface front (called Bai-u front) whose mean position is along the southern coast of Japanese Islands with the orientation from the northeast to the southwest.

During the later stage of this rainy season, we sometimes experience heavy rainfalls over Japanese Islands, especialiy over west and central Japan. The rainfall amounts to more than several hundreds of millimeter (i. e. two inches) during one or two days in its extreme case, causing wide-range floods and damages.

Many writers have studied structure and mechanism of such heavy frainfalls. They have recognized that, in some cases (Smith 1950) there exists a strong cold advection into area of heavy rainfall, and in other cases (Means 1954, Takahashi 1954, Nakayama 1956) the heavy rainfall is associated with a southerly jet at low levels which transports both heat and moisture into the area of heavy rains. Sometimes (Chapman and Carr 1952) both factors operate during a period of heavy rainfall. In many cases (Otani 1954) the moist tongue and convergence line are associated with heavy rainfall.

In addition to these phenomena, we some- times observe a kind of upper frontal zone in the mid- and upper troposphere accompanied with the heavy rainfall over Japan and vicinity (Tanaka et al 1954, Sugiura 1955), and the structure of this upper frontal zone gives us an impression that this frontal zone might be one of the main factors controlling the intensification of the rainfall during the rainy season of the early summer.

It is the purpose of this paper to show the analysis of heavy rainfalls at 25-26 June and 17-18 July 1953 over west and central Japan, and to propose a possible mechanism for the heavy rainfall during early summer, laying stress on the importance of the horizontal convergence which is associated. with the mid-troposphere subtropical frontal zone.

\section{The heavy rainfall on 26 June 1953}

Surface situation.-A weak wave cyclone $(998 \mathrm{mb})$ on a semi-stationary front was moving over the lower Yangtze River and Yellow Sea on 24th and 25th June 1953, and gradually became stationary on 26th over Korea. Fig. 1 shows the surface map at 15 GCT 25 (00 Japanese Time 26) June. The semi-stationary front which extended eastsoutheastward from the cyclone was located over Kyushu on 25th and 26th, and on these days northern Kyushu was attacked by extremely heavy rainfall.

Rainfall.-On the late morning of 25th the rainfall began over central Kyushu, and in the afternoon it gradually intensified and the 


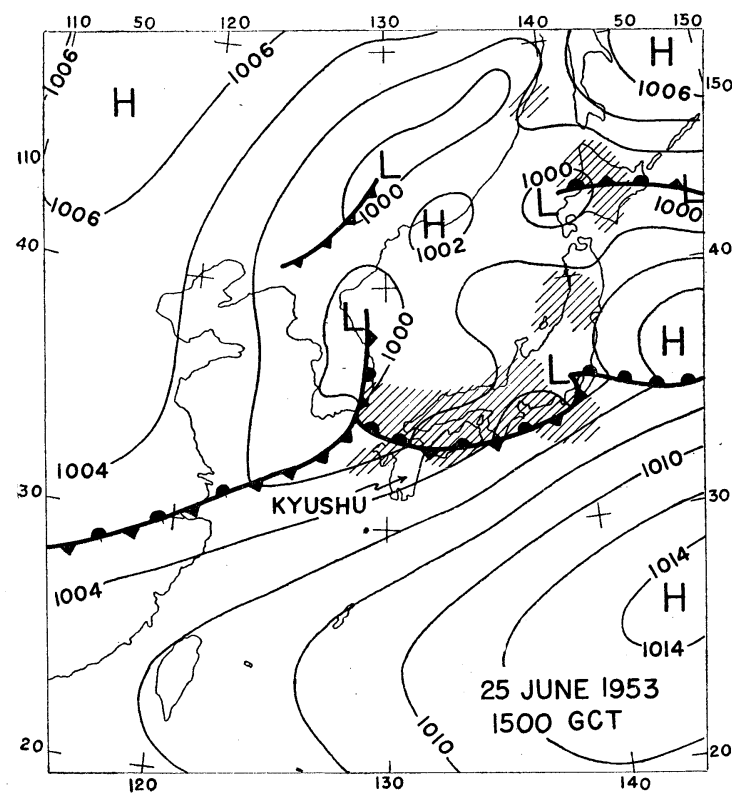

Fig. 1. Surface map at 15 GCT 25 June 1953. Shaded area shows rain.

rain area shifted northward as a whole. During the night of 25th and the morning of 26th extremely heavy rainfall was observed over northern Kyushu with maximum amount of more than $400 \mathrm{~mm}$ during 24 hours. On the morning of 26th the rain area began to shift southward, and during the whole day of 26th central Kyushu was under the heavy rainfall. Fig. 2 (a) and (b) show the distribution of 24 hour amount of the rainfall, (a) from $00 \mathrm{GCT} 25$ to $00 \mathrm{GCT} 26$, and (b) from $00 \mathrm{GCT} 26$ to $00 \mathrm{GCT} 27$ June. The patterns clearly show the characteristic zonal distribution in east-west direction, from which it is suggested that the mechanism of the rainfall has a zonal structure elongated in nearly east-west direction.

Upper flow pattern.-Figs. 3 and 4 show the $400 \mathrm{mb}$ and $300 \mathrm{mb}$ charts at $15 \mathrm{GCT}$ June 25, 1953. In $400 \mathrm{mb}$ chart a trough extends from North Korea to the west of Hokkaido. An approximately westsouthwesterly current was flowing over the southern side of this trough, and maximum wind area was located over southern Kyushu and southern Shikoku. Isotherms indicate that the warm air was covering over western Japan.

In the $300 \mathrm{mb}$ chart (Fig. 4) the current was

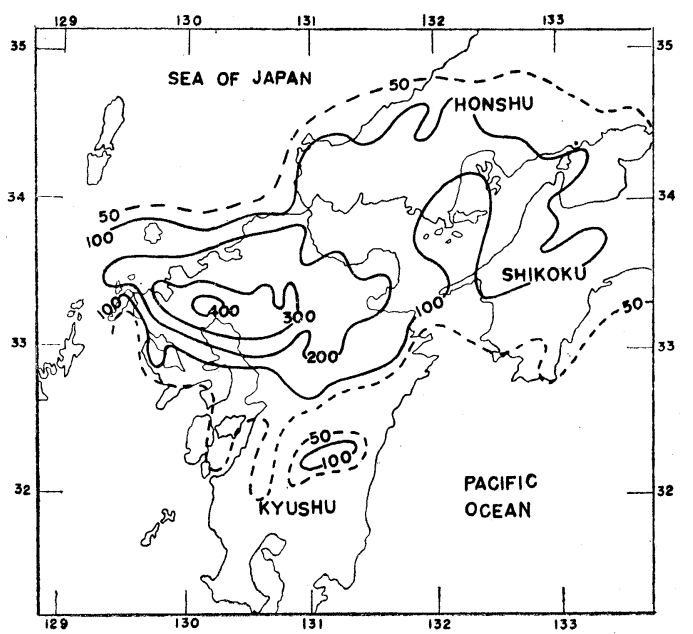

(a)

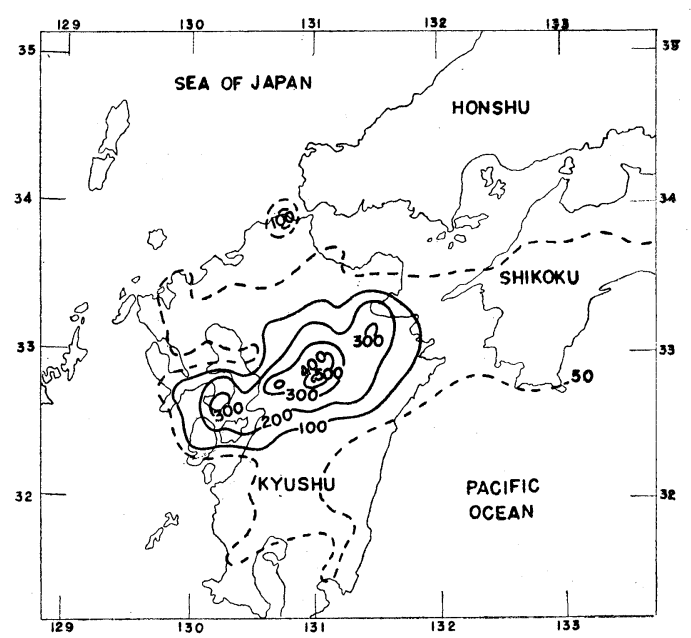

(b)

Fig. 2. Distribution of rainfall amount (in $\mathrm{mm}$ ) over Kyushu. (a) for 00 GCT 25-00 GCT 26 June. (b) for 00 GCT 26-00 GCT 27 June 1953.

approximately westsouthwesterly over Kyushu and west Japan, and the general conditions were almost the same as those in $400 \mathrm{mb}$ chart. The subtropical front which is determined by vertical cross sections at this time, is shown by thick lines in Figs. 3 and 4 .

Cross sections.-Figs. 5 and 6 show cross sections at 15 GCT 25th June over Korea and Kyushu along a thin line (A) shown in Fig. 3. Fig. 5 shows wind and temperature fields. Fig. 5 shows humidity field.

In Figs. 5 and 6 the main characteristic is a distinct frontal zone in the mid-and upper troposphere over Sachon (104) and Itazuke 


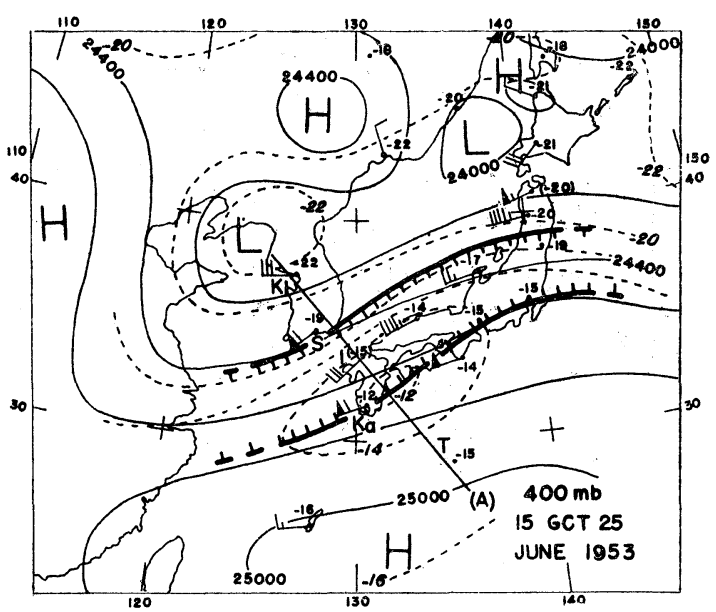

Fig. 3. $400 \mathrm{mb}$ chart at 15 GCT 25 June 1953. At stations, full wind barb 10 knots, triangle 50 knots; temperature in deg C. Thin solid lines: contours (interval $200 \mathrm{ft}$ ); dashed lines: isotherms (interval $2^{\circ} \mathrm{C}$ ). Thick lines show the substropical frontal zone. Thin straight line $(A)$ indicates location of cross sections (Figs. 5, 6, 7, 9 and 10). Stations: $K i$, Kimpo (208); S, Sachon (104); $I$, Itazuke (808); $K a$, Kagoshima (827); $T$, Tango (ship).

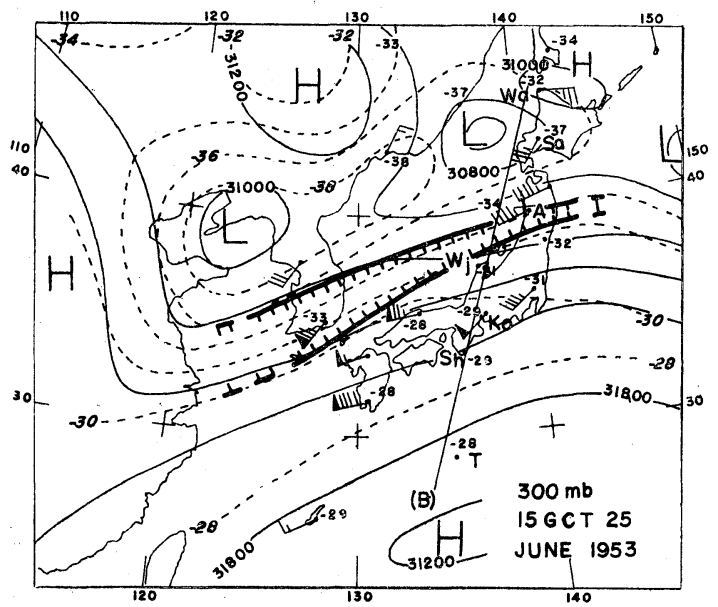

Fig. 4. $300 \mathrm{mb}$ chart at 15 GCT 25 June 1953. Legend of winds, contours and isotherms same as fig. 4. Thick lines show the subtropical frontal zone. Thin straight line $(B)$ indicates location of cross section (Figs. 8, 15 and 16). Stations: $W a$, Wakkanai (401); Sa, Sapporo (412); A, Akita (582); $W j$, Wajima (600); Ko, Komaki (635); Sh, Shionomisaki (778); $T$, Tango (ship).

(808). The southern end of the lower boundary line of this frontal zone which is distinctly determined by significant points at $250 \mathrm{mb}$ of Kimpo (208) and $350 \mathrm{mb}$ of Sachon, gradually becomes indistinct over Itazuke. Judging from its potential temperature and from its relation to the polar front in the lower troposphere over Sachon and Kimpo, this lower boundary line is considered as a southern

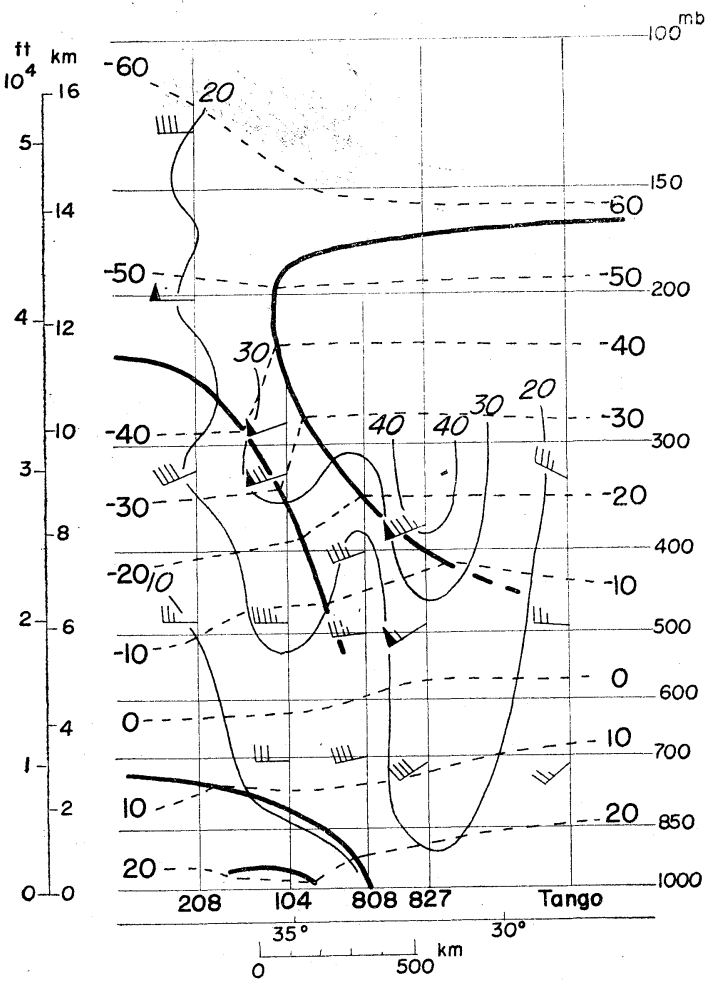

Fig. 5. Meridional cross section along line $(A)$ in Fig. 3, 15 GCT 25 June 1953. Thin solid lines, isotachs of total wind speed $\left(\mathrm{m} \mathrm{sec}^{-1}\right)$; thin dashed lines, isotherms $(\operatorname{deg} C$ ). Full wind barb 10 knots, triangle 50 knots. Heavy lines, boundaries of principal stable layers.

portion of the polar front tropopause (abbreviated as p.f. tropopause hereafter). The configuration of this upper frontal zone is the same as that of the subtropical front which has been discussed by the writer in the previous papers (Mohri 1956 (a), 1956 (b)). The observed wind field and temperature field suggest that a jet stream is possibly situated near $200 \mathrm{mb}$ level over Sachon and Itazuke.

Meridional distribution of the humidity field in Fig. 6 shows a remarkable feature in the mid-troposphere. A dry air is observed 


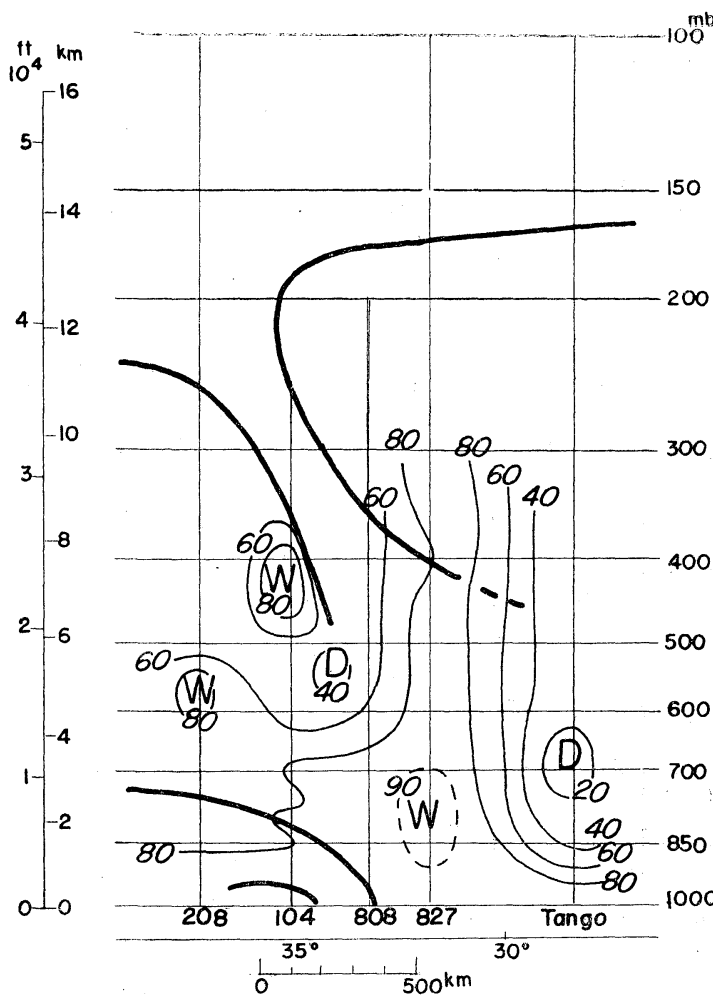

Fig. 6. Meridional cross section along line $(A)$ in Fig. 3, 15 GCT 25 June 1953. Thin solid lines, equal humidity lines (\%), with temporary dashed lines for the intermediate humidity; heavy lines, boundaries of principal stable layers. $D$, dry; $W$, wet area.

over Itazuke and Sachon associated with the southern end of the p.f. tropopause, whereas a very moist air is observed in a deep layer over Kagoshima (827) and in the lower troposhere over Itazuke. The moist air over Kagoshima is located above the rainfall area observed simultaneously on the surface stations.

Fig. 7 shows the horizontal divergence at 15 GCT 25 June, corresponding to the cross sections of Figs. 5 and 6 . The horizontal divergence $\partial u / \partial x+\partial v / \partial y$ is calculated from the observed wind field, analysing $u$ (eastcomponent) and $v$ (north-component) for every kilometer level with mesh size $200 \mathrm{~km}$ for $\Delta x$ and $\Delta y$. The main feature of Fig. 7 is the horizontal convergence area in the lower and mid-troposphere associated with the surface polar front and the subtropical frontal zone. This convergence area indicates the ascending motion of the moist tropical air in

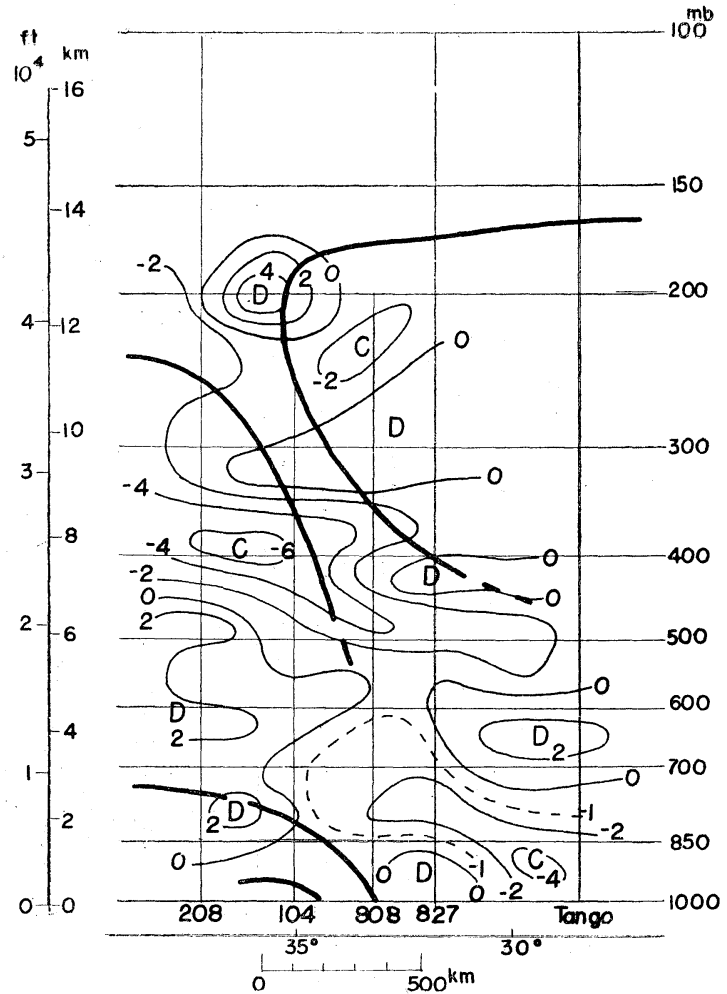

Fig. 7. Meridional cross section along line $(A)$ in Fig. 3, 15 GCT 25 June 1953. Thin solid lines, equal horizontal divergence $(\partial u / \partial x+\partial v / \partial y)$ line (in $\left.10^{-5} \mathrm{sec}^{-1}\right)$, with temporary dashed lines for the intermediate value; heavy lines, boundaries of principal stable layers. $D$, divergence; $C$, convergence.

the lower and mid-troposphere over Kyushu, showing the same conditions as the humidity field in Fig. 6.

Fig. 8 shows a vertical cross section at 15 GCT 25 June along a thin line (B) in Fig. 4. In Fig. 8 we can observe a very distinct subtropical frontal zone in the mid- and upper troposphere over northern Honshu, and a jet stream near $200 \mathrm{mb}$ level over Akita (582).

The horizontal dimension of the subtropical frontal zone as shown in Figs. 3 and 4 indicates that this is not a local phenomenon, but has a large horizontal dimension of at least more than $1000 \mathrm{~km}$ in east-west direction over Japan and vicinity.

Figs. 9 and 10 are the cross sections at 03 GCT 26 June, twelve hours later than Figs. 5 and 6 . Fig. 9 shows wind and temperature fields, and Fig. 10 shows humidity field. Similar conditions of temperature fields, as 


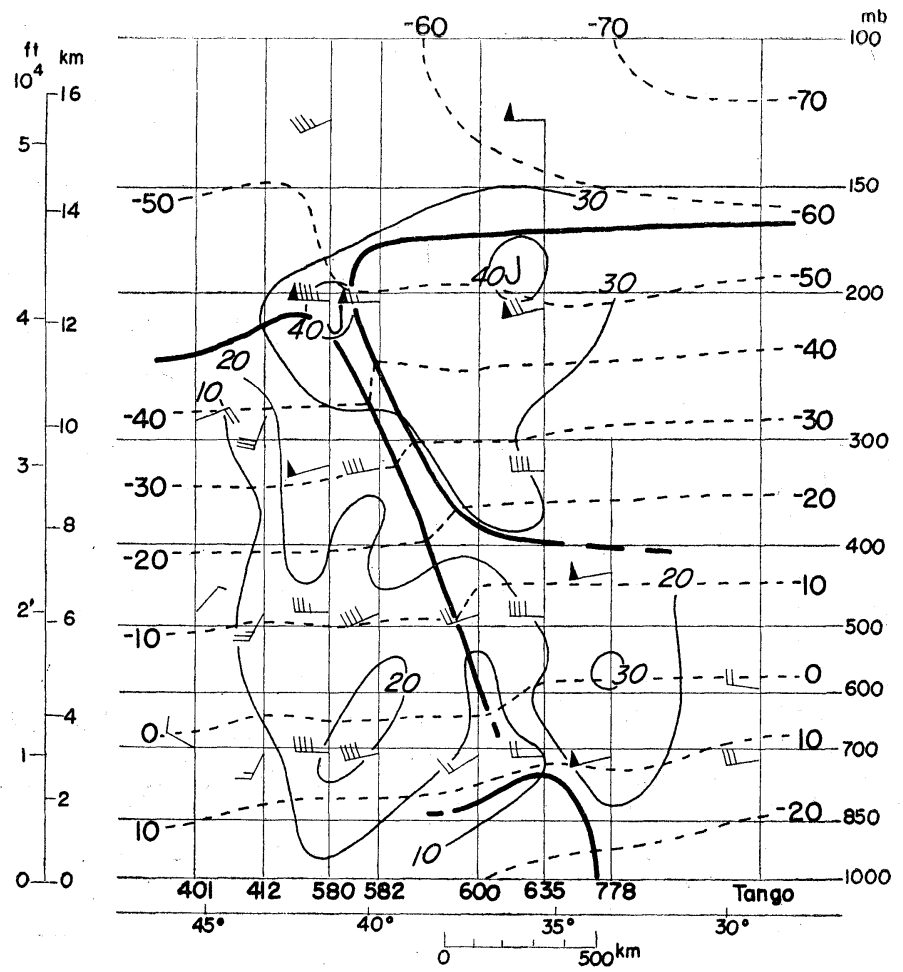

Fig. 8. Meridional cross section along line $(B)$ in Fig. 4, 15 GCT 25 June, 1953. Legend same as Fig. 5. $J$, jets.

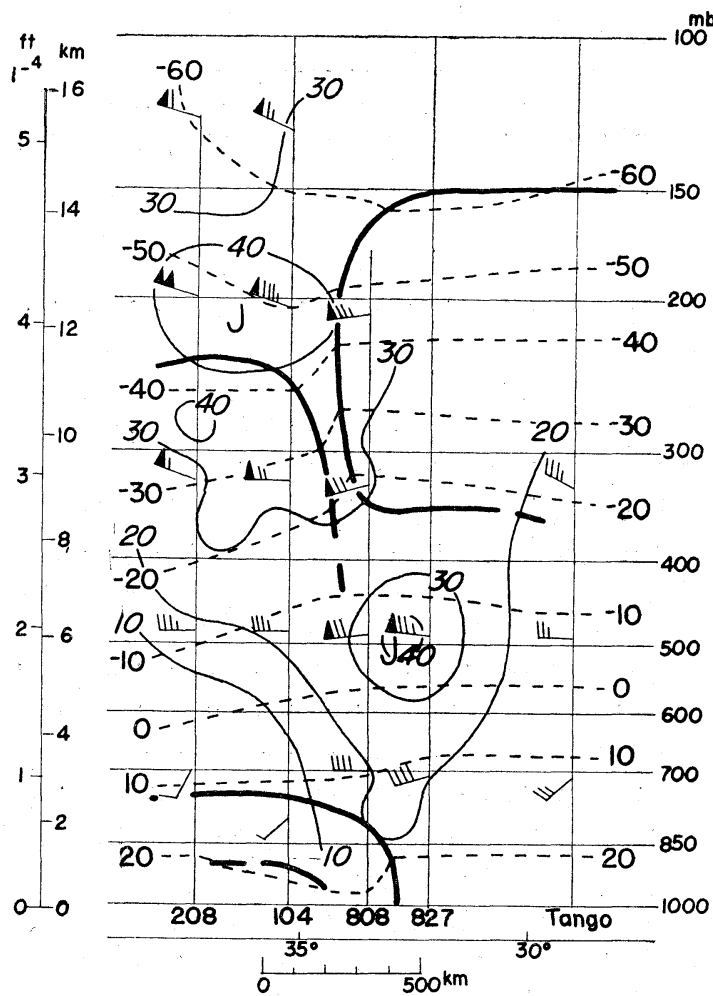

Fig. 9. Meridional cross section along line $(A)$ in Fig. 3, 03 GCT 26 June, 1953. Legend same as Fig. $5 . J$, jets.

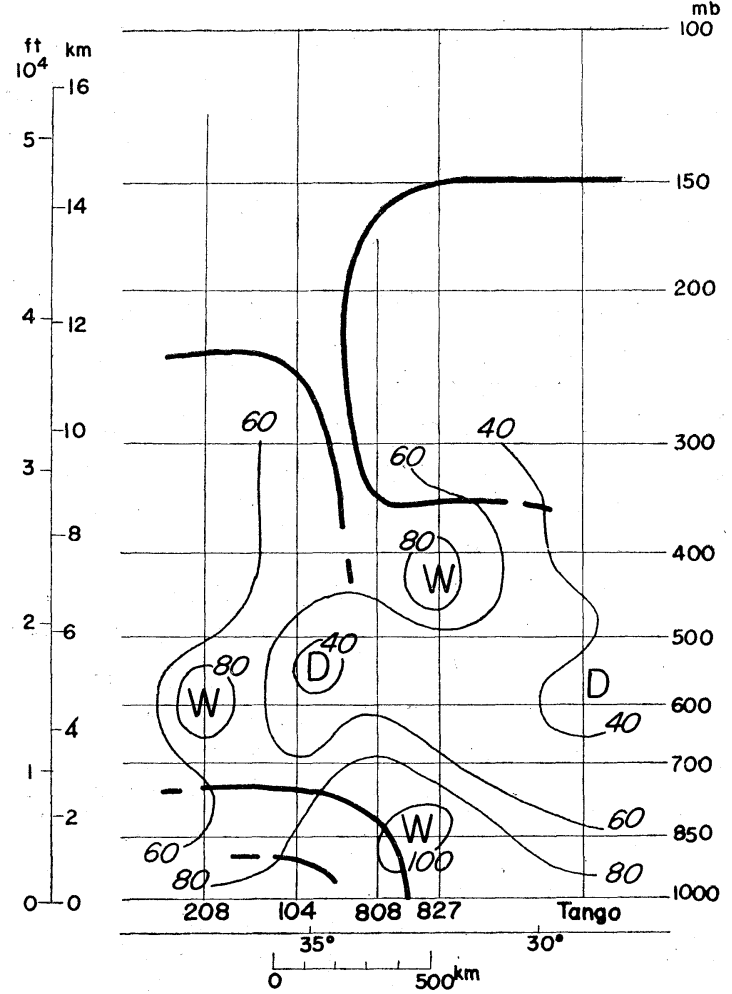

Fig. 10. Meridional cross section along line $(A)$ in Fig. 3, 03 GCT 26 June, 1953. Legend same as Fig. 6. 
in Figs. 5 and 6 are observed in Figs. 9 and 10 , with a more narrow transitional zone of the subtropical frontal zone in the upper troposhere. One difference of Fig. 10 from Fig. 6 the existence of a dry area in the mid-troposphere over Kagoshima. When the humidity field over Kyushu in Fig. 6 is compared with that in Fig. 10, it is noticed that the dry area shifts southward in the midtroposphere during twelve hours from 15 GCT 25 th to 03 GCT 26th. This fact is easily understood if we remember that the rainy area shifted southward from north Kyushu to central Kyushu during these hours.

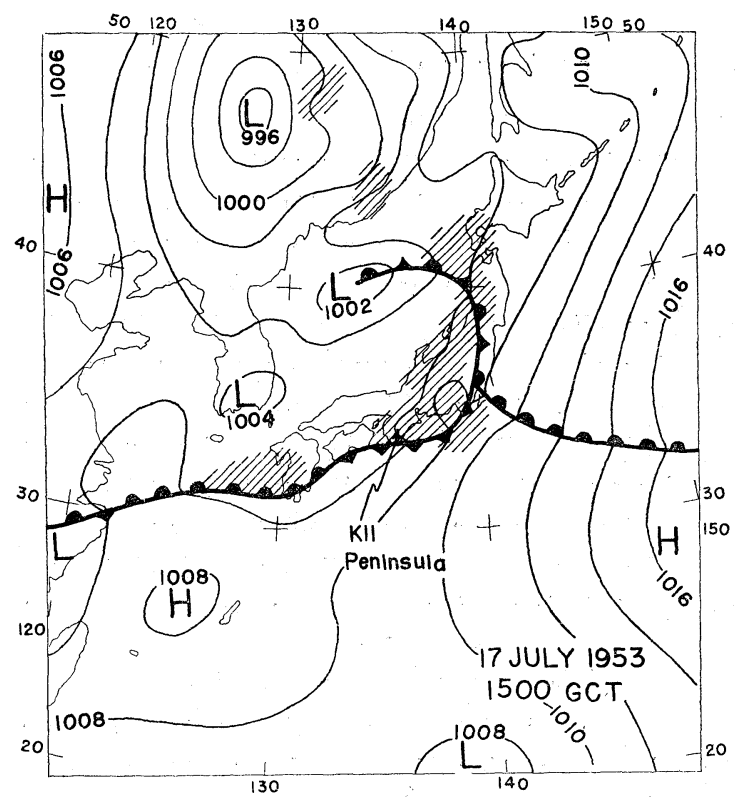

Fig. 11. Surface map at 15 GCT 17 July 1953. Shaded area shows rain.

\section{The heavy rainfall at 17 July 1953}

Surface situation.-A weak cyclone $(998 \mathrm{mb})$ moved slowly eastward over the western part of the Sea of Japan on 16 July 1953, and gradually weakened and became stationary over the central part of the Sea of Japan on 17th, and finally disappeared on 18th. Fig. 11 shows the surface map at $15 \mathrm{GCT} 17$ th July. A warm front which extended southward from the center of the cyclone was located over Kyushu on 16th, and passed central Japan in the afternoon of 17 th shifting from west to east. A cold front which stretched

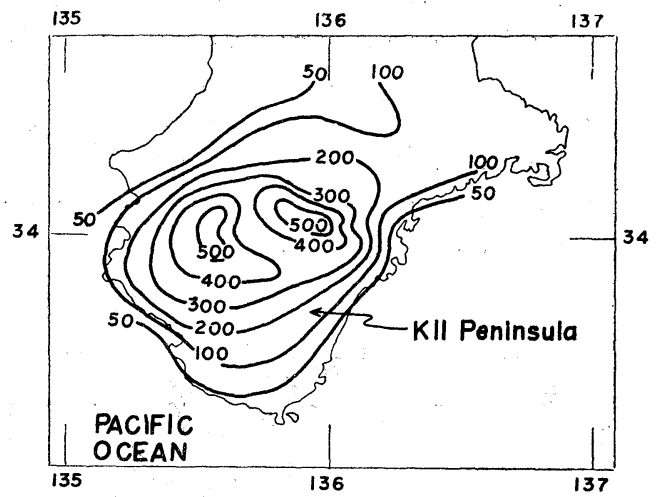

Fig. 12. Distribution of rainfall amount (in $\mathrm{mm}$ ) over Kii Peninsula for 00 GCT 17-00 GCT 18 July, 1953.

southwestward from the center of the cyclone passed central Japan in the afternoon of 17th. An extremely heavy rainfall was observed over Kii Peninsula when this cold front passed there.

Rainfall.-The heavy rainfall over Kii Peninsula began in the evening of $17 \mathrm{th}$ and reached to its maximum about midnight and began to weaken in the morning of 18 th, ending in the late morning of 18th. The heaviest rainfall was observed over mountain regions with the hourly maximum amount of $70 \mathrm{~mm}$ (3 inches) in extreme case, resulting nearly $500 \mathrm{~mm}$ in total amount during several or 10 hours. The 24 hour amount of rainfall from $00 \mathrm{GCT} 17$ to $00 \mathrm{GCT} 18 \mathrm{July}$ shown in Fig. 12.

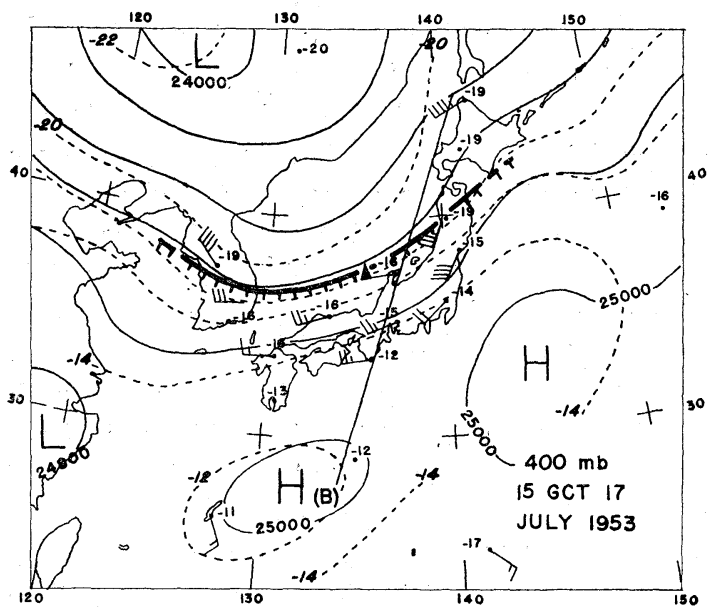

Fig. 13. $400 \mathrm{mb}$ chart at 15 GCT 17 July 1953. Legend same as Fig. 4. 
Upper flow pattern.--Figs. 13 and 14 show the $400 \mathrm{mb}$ and $300 \mathrm{mb}$ charts at $15 \mathrm{GCT} 17$ July 1953. In Figs. 13 and 14 a low area is located over northeastern Manchuria, and southwesterly or westerly current is flowing over Japanese Islands. In Fig. 14 a jet is observed from central Korea to northern Honshu, and a subtropical front is clearly shown.

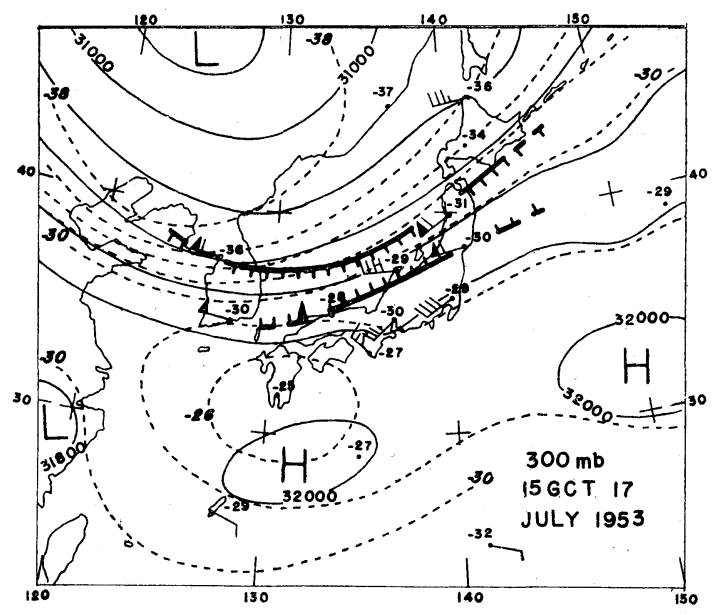

Fig. 14. $300 \mathrm{mb}$ chart at 15 GCT 17 July 1953. Legend same as Fig. 4, except line $(B)$ and stations.

Cross sections.-Figs. 15 and 16 show the cross sections along line (B) in Fig. 13 at 15 GCT 17 th July $1953 . \quad$ Fig. 15 shows wind and temperature fields, and Fig. 16 shows humidity field.

A main characteristic in Figs. 15 and 16 is, again, a distinct frontal zone in the upper and mid-troposphere over the stations of north and central Japan. Figs. 15 and 16 correspond to the time of the maximum heavy rainfall over Kii Peninsula. The lower boundary of the upper frontal zone is distinct at Misawa (580) and Akita (582), but becomes more or less vague over Wajima (600). This lower boundary is considered as a southern part of the p.f. tropopause.

In Fig. 16 an extremely dry area with minimum humidity $10 \%$ in mid-troposphere over Wajima is associated with that part of the p.f. tropopause, while a very moist area is observed in the lower troposphere over Komaki (635) and Shionomisaki (778). This fact suggests us that there exists a strong south-north gradient of the vertical motion, with subsidence over Wajima and upward motion over Shiomonisaki.

The heavy rain which occurred over Kii Peninsula during night from 17th to 18 th is evidently associated with the surface front which passed through the peninsula at this time. In Figs. 15 and 16 this surface front is located between Komaki and Shionomisaki. However, the south-north humidity contrast which appears in the mid-trpposphere above the heavy rainfall area is related to the southern end of p.f. tropopause. This fact suggests that the subtropical front is somewhat associated to the heavy rainfall described above.

\section{Discussions on the mechanism of the heavy rainfall.}

The heavy rainfall over south Japan during the early summer is usually associated with the semi-stationary surface front (i.e. Bai-u front) and the unstable moist air coming from the southern seas. Now, problem is what produces the convergence and upward motion of such moist air which results in the heavy rainfall over the south Japan. The southerly moist current is of southwesterly and southeasterly monsoon and usually has dry inversion layer at about $850 \mathrm{mb}$ level. The air under this inversion layer is very moist while the air above is very dry, as is often observed in the tropical latitudes.

In case of the heavy rainfall this strong vertical stability in the lower troposphere should be destroyed and the convective instability should be induced in the deep layer. Factors which would contribute to the vertical instability will be discussed briefly in the following.

First, one of the simple ways to ascend the moist air might be the upsloping motion along the mountain sides. The rainfall of 17th and 18th July 1953 over Kii Peninsula was definitely heavy over the mountain regions, and the convective instability induced by the upsloping motion along the mountain sides was one of the main factors for the heavy rainfall. Hewever, the rainfall of 25 th and 26th June 1953 was heavy over the flat ground as well as over the mountain regions. Moreover, in this case as described in paragraph 


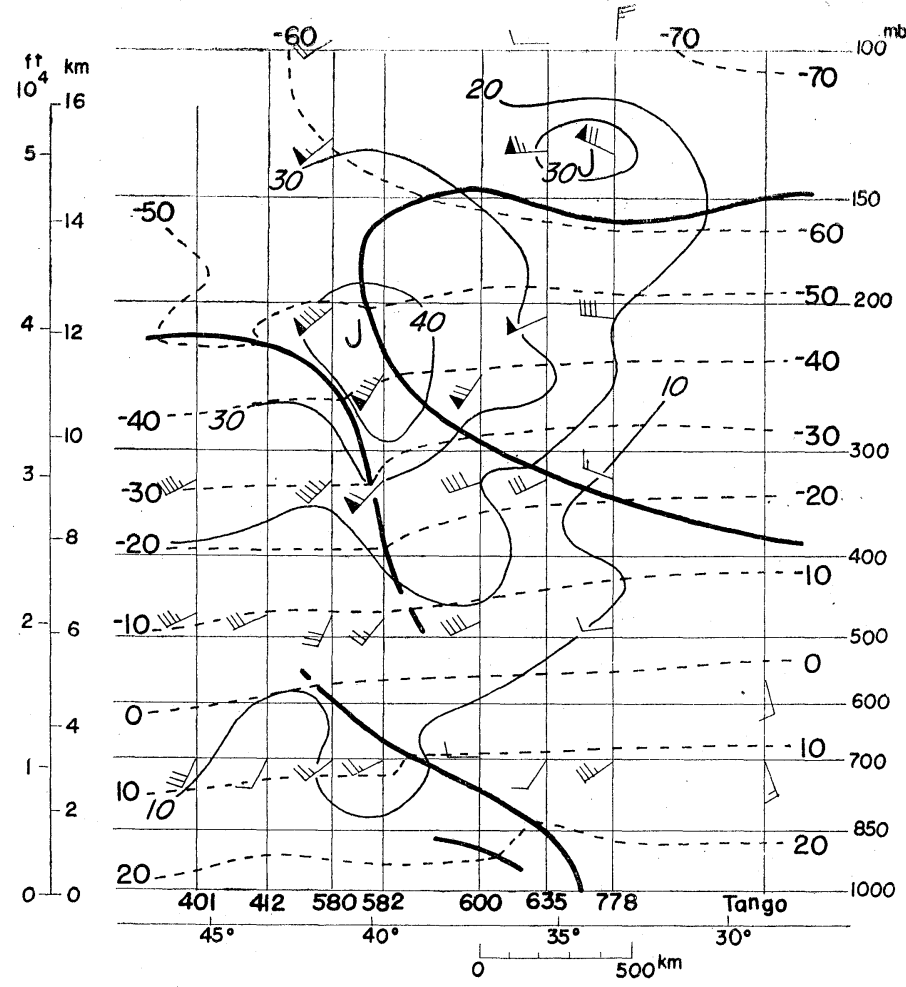

Fig. 15. Meridional cross section along line $(B)$ in Fig. 13, 15 GCT 17 July 1953. Legend same as Fig. 5 . $J$, jets.

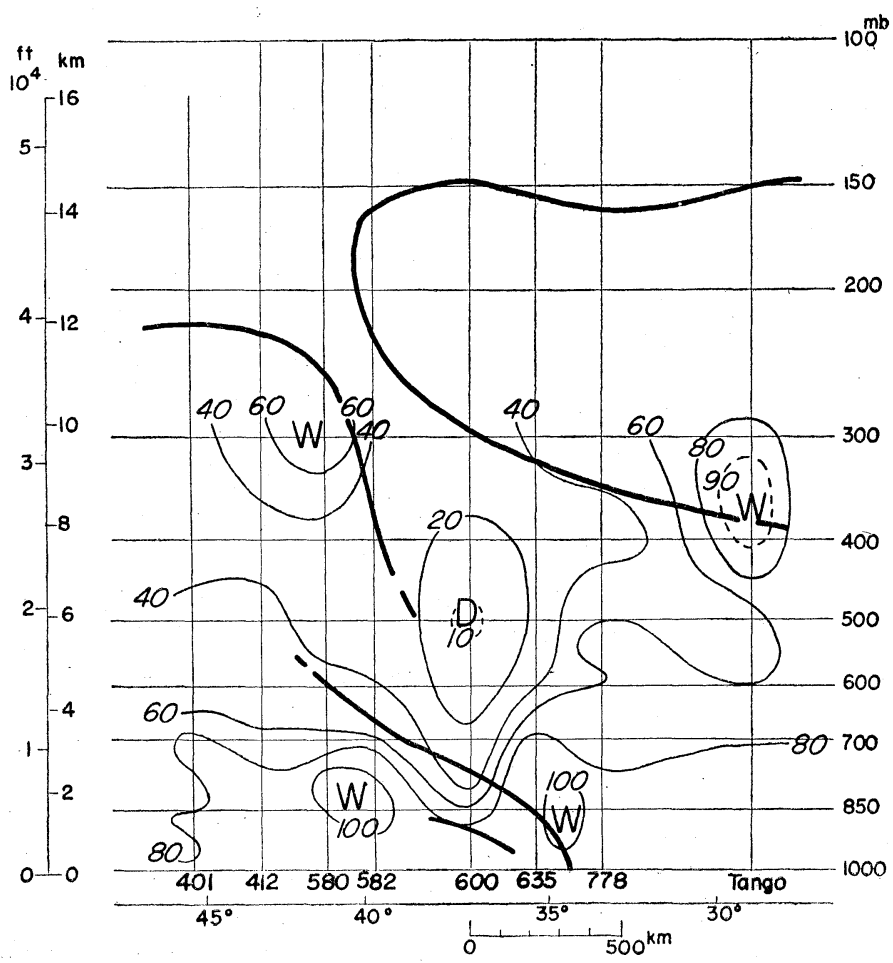

Fig. 16. Meridional cross section along line $(B)$ in Fig. 13, 15 GCT 17 July 1953. Legend same as Fig. 6. 
2 , the rainfall region was elongated along east-west direction, and slowly fluctuated in north-south direction as a whole. Then, we are lead to the suggestion that the latter heavy rainfall should be associated not only with the upsloping motion along the mountain sides but also with the upward motion along a kind of frontal system, and that the rainfall area moves in north-south direction according to the movement of the convergence zone of the frontal system.

Secondly, the upslope motion above the surface front (i.e. Bai-u front) may be one of the main factors for the rainfall. However, a surface front is usually shallow as is shown on Figs. 5, 9 and 15, and would not be so decisive as to bring out the heavy rainfall described above. It seems that a relatively deep convergence zone in the mid-troposphere should be necessary to pour down the heavy rainfall.

Thirdly, a sort of convergence which appears in the form of a convergence line or instability line in the southwesterly or southeasterly monsoons, or a confluence zone between southwesterly and southeasterly monsoon currents may be one of the important factors for the heavy rainfall. This sort of convergence zone is usually formed by the relatively wider scale confluence between two or three currents. However, even though this sort of convergence is very important for the heavy rainfall, it might not be sufficient to explain the mechanism of the heavy rainfall over Japan. Additional mechanism might be needed to explain why the heavy rainfall area is elongated in eastwest direction, as in the case of 25-26 June 1953.

Thus, the writer tries to propose additional mechanism for the heavy rainfall during the Bai-u season. As described above, the cross sections (Figs. 5, 6, 7, 8, 9, 10, 15 and 16) clearly show that the p.f. tropopause (the lower boundary of the subtropical frontal zone) is very distinct in the mid- and upper troposphere in case of the heavy rainfall.

A subtropical frontal zone is usually closely associated with the subtropical jet stream especially in its accelerating stage (Mohri 1956 (a)). The juxtaposition of the cold dry air to the north and the warm moist air to the south of the p.f. tropopause is closely connected with the circulation about the subtropical jet which separates the tropical cell from the westerlies in the middle latitudes. The horizontal convergence associated with the southern boundary of the p.f. tropopause produces the confluence of cold dry air and warm moist air. Thus, this type of horizontal convergence could be responsible to the following characteristics of the heavy rainfall combined with the convectional instability of the moist air.

First, the rainfall could be heavy even on the plain. Secondly, the east-westward elongated pattern of the rainfall amount could be closely connected with the horizontal dimension of the p.f. tropopause and the subtropical frontal zone. Slight fluctuation of the general pattern in north-south direction is thus possibly related with the general movement of the p.f. tropopause. Thirdly, the eastward shifting of the maximum rainfall area could be related with the eastward slow movement of the p.f. tropopause and local maximum center of the jet, perhaps changing its intensity of the convergence with time.

Summing up the above discussion, it is suggested that the horizontal convergence associated with the southern end of the p.f. tropopause may be one of the main factors for the heavy rainfall during the Bai-u season over west and central Japan.

\section{Acknowledgement}

The writer expresses his cordial thanks to Dr. Koenuma, Chief of Forecasting Department, and to Mr. Itoo, Chief of Forecast Section, for their encouragement to this study. Cordial thanks are also due to Mr. Suda who kindly read this paper before the general meeting of the Meteorological Society of Japan on 18 May 1956.

\section{References}

1. Chapman, W. T., and J. A. Carr (1952): Heavy rainfall over northeastern Wyoming and southern Montana, May 21, 1952. Mon. Wea. Rev., 80, 88-93, 
2. Means, I. I. (1954): A study of the mean southerly wind maximum in low levels associated with a period of summer precipitation in the middle west. Bull. Amer. Meteor. Soc., 35, 166-170.

3. Mohri, K. (1956) (a): An analysis of jet streams over Japan on 3 November 1952. Journ. Met. Soc. Japan., 34, 29-33.

4. (1956) (b): On the characteristic structure in the mid-tropospheric westerlies accompanied with recurved typhoons. Geophys. Mag., 27, 237-247.

5. Nagayama, M. (1956): Some considerations on the heavy rainfall over Kyushu district in the third decade of June, 1953. Journ. Met. Research, 8, 84-93. (in Japanese).
6. Otani, T. (1954): Converging line of the northeast trade wind and converging belt of the tropical air current. Geophys. Mag. 25, 1-122.

7. Smith, C. D., Jr. (1950): The intense Pacific coast storms of October 26-28, 1950. Mon. Wea. Rev., 78, 191-195.

8. Sugiura, S. (1955): Forecasting of heavy rainfall by premigram. Journ. Met. Research, $\mathbf{7}$, 31-39. (in Japanese)

9. Takahashi, et al. (1954): Analysis of extraordinarily heavy rains at the end of Baiu. Journ. Met. Soc. Japan., 32, 29-37.

10. Tanaka, et al. (1954): A heavy rainfall over Kyushu in last decade of June 1953. Memoirs. C.M.O., 38, 303-312 (in Japanese) 